\title{
Ovarian Fibroma
}

National Cancer Institute

\section{Source}

National Cancer Institute. Ovarian Fibroma. NCI Thesaurus. Code C3498.

A benign neoplasm arising from soft tissue of the ovary. It is characterized by the presence of spindle-shaped fibroblasts. 